\title{
Using the National Death Index to Identify Duplicate Cancer Incident Cases in Florida and New York, 1996-2005
}

\author{
Brad Wohler, MS; Baozhen Qiao, PhD; Hannah K. Weir, PhD; Jill A. MacKinnon, PhD; \\ Maria J. Schymura, PhD
}

\begin{abstract}
Suggested citation for this article: Wohler B, Qiao B, Weir HK, MacKinnon JA, Schymura MJ. Using the National Death Index to Identify Duplicate Cancer Incident Cases in Florida and New York, 1996-2005. Prev Chronic Dis 2014;11:140200. DOI: http:// dx.doi.org/10.5888/pcd11.140200.
\end{abstract}

\section{PEER REVIEWED}

\section{Abstract}

\section{Introduction}

Cancer registries link incidence data to state death certificates to update vital status and identify missing cases; they also link these data to the National Death Index (NDI) to update vital status among patients who leave the state after their diagnosis. This study explored the use of information from NDI linkages to identify potential duplicate cancer cases registered in both Florida and New York.

\section{Methods}

The Florida Cancer Data System (FCDS) and the New York State Cancer Registry (NYSCR) linked incidence data with state and NDI death records from 1996 through 2005. Information for patients whose death occurred in the reciprocal state (the death state) was exchanged. Potential duplicate cases were those that had the same diagnosis and the same or similar diagnosis date.

\section{Results}

NDI identified 4,657 FCDS cancer patients who died in New York and 2,740 NYSCR cancer patients who died in Florida. Matching identified 5,030 cases registered in both states; 508 were death certificate-only (DCO) cases in the death state's registry, and 3,760 (74.8\%) were potential duplicates. Among FCDS and NYSCR patients who died and were registered in the registry of the reciprocal state, more than $50 \%$ were registered with the same cancer diagnosis, and approximately $80 \%$ had similar diagnosis dates (within 1 year).

\section{Conclusion}

NDI identified DCO cases in the death state's cancer registry and a large proportion of potential duplicate cases. Standards are needed for assigning primary residence when multiple registries report the same case. The registry initiating the NDI linkage should consider sharing relevant information with death state registries so that these registries can remove erroneous DCO cases from their databases.

\section{Introduction}

In the United States, there is a population-based cancer registry in all 50 states, Puerto Rico, the US Pacific Island jurisdictions, the District of Columbia, and 6 metropolitan areas funded by the Centers for Disease Control and Prevention's (CDC's) National Program of Cancer Registries (NPCR) and/or the National Cancer Institute's (NCI's) Surveillance, Epidemiology, and End Results (SEER) Program. Registries collect information on all residents newly diagnosed with or treated for cancer in their catchment areas and report de-identified data to their federal surveillance programs and to the North American Association of Central Cancer Registries (NAACCR), where the data are combined for the purpose of reporting national, regional, and state cancer incidence data $(1-4)$.

Cancer registries collect data using procedures and codes promulgated by NAACCR (5), including personal and demographic data (eg, name, social security number, birth date, race/ethnicity, sex, residence at diagnosis) and case data (eg, date of diagnosis, primary site, histology, behavior). Cancer patients can be dia- 
gnosed with multiple primary cancers; therefore, each cancer case is assigned a sequence number according to the temporal order in which it was diagnosed. Registries also collect follow-up information, including data on vital status (alive or dead), date of last contact, and cause of death.

Deaths are recorded by the vital records office in the state where the death occurred, and if applicable, the death certificate is forwarded, per data-exchange agreement, to the vital records office in the state where the person resided at the time of death. Each year, cancer registries perform death clearance (6), the process by which registries link their incidence data with their state death certificates to identify cancer patients who may have been missed by the registry at the time of their diagnosis and to update vital status (deaths) among registered cancer patients. If no information is found in the registry for a cancer diagnosis on these death certificate-initiated cases, they are registered as death certificate-only (DCO) cases in the cancer registry's database.

However, patients may move out of state between the time of their diagnosis and their death. When an incident record does not match with a state death certificate record, the cancer registry may send patient personal and demographic data for linkage with CDC's National Death Index (NDI) (7). The NDI is a repository of death certificate information from vital statistics offices in all 50 states, the District of Columbia, and Puerto Rico. To encourage NDI linkages, $\mathrm{CDC}$ and NCI have arranged for NDI linkage services to be available at no cost to the registries.

An accurate count of incident cases is necessary for understanding the burden of cancer in the population and for planning health resources to meet the growing cancer burden. However, the data that are reported to the federal surveillance programs do not contain personal identifiers and, therefore, it is not possible to identify duplicate cases - incident cases that have the same diagnosis and similar diagnosis dates and are reported by 2 or more cancer registries. Duplicate case reporting can lead to over-counting incident cases and create an inaccurate picture of the cancer burden at the state and national levels.

The Florida Cancer Data System (FCDS) and the New York State Cancer Registry (NYSCR) routinely perform death clearance with their state death certificate records, and both have sent personal and demographic data on incident cases to NDI. The objective of this study was to explore the use of information from NDI linkages to identify potential duplicate cancer cases registered in both the FCDS and the NYSCR.

\section{Methods}

\section{Source of data}

The FCDS began as a population-based cancer registry in 1981 and received funding from NPCR for the reporting of incidence data beginning in 1995. The FCDS registers approximately 100,000 new incident cases per year. The NYSCR has been population-based since 1976 and received funding from NPCR for the reporting of incidence data beginning in 1996. The NYSCR registers approximately 100,000 new incident cases per year. Both registries conduct annual death clearance and in 2008, both registries sent data to NDI for linkage to information on deaths that occurred through December 31, 2005.

Per agreement with NCHS, the registry that initiates the NDI linkage may share NDI-derived information (except for cause of death) with the cancer registry in the state where the death occurred (death state) to determine whether the cancer patient was registered in that state's cancer registry. Both FCDS and NYSCR have agreements that allow for the exchange of data between the 2 registries.

Common procedures were used to prepare data for linkage with NDI and process linkage results (8). FCDS staff identified deaths in New York among cancer patients registered in the FCDS; conversely, NYSCR staff identified deaths in Florida among cancer patients registered in the NYSCR. Exchange files were prepared by each registry; the files included personal and demographic information (name, birth date, social security number, sex, and race/ ethnicity), case information (diagnosis date, primary site, histology, behavior, laterality, sequence number, and type of reporting source), and data from the NDI linkages (death date, death certificate number). Each record included a 5-digit SEER site recode, which was assigned on the basis of information on primary site and histology (9). When a patient had multiple cancer diagnoses, information on all cases was included in the exchange files.

\section{Data linkage and analysis}

We examined linkage between the FCDS and NYSCR and their state death certificate records and the NDI for deaths from 1996 through 2005 among cancer cases diagnosed during the same period. Exchange files were matched to the cancer registry database by using algorithms developed by the registry. If a match was found, further comparisons were made, including whether the incident case was registered as a single primary (ie, only) cancer or one of multiple primary cancers, whether the case was registered as a DCO case in the death state registry, and whether the SEER site codes matched. If the match was not a DCO case, and if the first 4 digits of the SEER site recode were the same, the diagnosis

\footnotetext{
The opinions expressed by authors contributing to this journal do not necessarily reflect the opinions of the U.S. Department of Health and Human Services, the Public Health Service, the Centers for Disease Control and Prevention, or the authors' affiliated institutions.
} 
dates were compared for Florida residents who died in New York and were registered in the NYSCR and for New York residents who died in Florida and were registered in the FCDS.

\section{Results}

In Florida, 997,290 cancer cases were diagnosed among Florida residents and registered in the FCDS (Table 1). During the same period, 434,526 deaths were reported among these cancer patients. Linkage with state death certificate records identified 398,196 (91.6\%) deaths, all of which occurred in Florida, and linkage with NDI identified 36,330 (8.4\%) additional deaths. Among NDIidentified deaths, 3,464 occurred in Florida and 32,866 occurred outside of Florida; 4,657 of these occurred in New York.

In New York, 952,663 cancer cases were diagnosed among New York residents and registered in the NYSCR (Table 1). During the same period, 401,463 deaths were reported among these patients. Linkage with state death certificate records identified 389,164 $(96.9 \%)$ deaths; of these, 383,343 occurred in New York and 5,821 occurred outside of the state; approximately $26 \%$ occurred in Florida. Linkage with NDI identified 12,299 (3.1\%) additional deaths. Among NDI-identified deaths, 1,398 occurred in New York and 10,901 deaths occurred outside of New York; 2,740 (25\%) deaths occurred in Florida.

Of the 2,740 patients who were registered in the NYSCR and died in Florida, $66.0 \%(1,808 / 2,740)$ matched to a patient in the FCDS database (Table 2). Among matched patients, $15.2 \%(275 / 1,808)$ were registered as a single primary DCO case and $69.0 \%(1,248 /$ $1,808)$ were registered with at least 1 record indicating the same diagnosis site reported by the NYSCR.

Of the 4,657 patients who were registered in the FCDS and died in New York, $69.2 \%(3,222 / 4,657)$ matched to a patient in the NYSCR database (Table 2). Among matched patients, 7.2\% (233/ 3,222 ) were registered as a single primary DCO case and $78.0 \%$ $(2,512 / 3,222)$ were registered with at least 1 record indicating the same diagnosis site reported by FCDS.

Of the 3,760 patients registered in both the FCDS and NYSCR, 4,035 potential duplicate cancer cases were identified: 948 (23.5\%) lung and bronchus, $472(11.7 \%)$ colorectal, 373 (9.2\%) female breast cancer, $358(8.9 \%)$ prostate cancer, $266(6.7 \%)$ urinary bladder, and 1,618 (40.1\%) other cancers (Table 3). Among matched cases, the difference between the diagnosis dates was 6 months or less for $73.7 \%$ of cases, 1 year or less for $81.7 \%$ of cases, and more than 2 years for $12.3 \%$ of cases; and $72.2 \%$ of all matched cases were reported as a single primary case in the cancer registry.

\section{Discussion}

This study provides evidence that cancer patients were registered in both the FCDS and the NYSCR, and that linkage with the NDI identified DCO cases that could be removed from the registry in the state where the death occurred. NDI linkages also identified potential duplicate cancer cases. Procedures are needed for determining residence at diagnosis for cancer patients registered in more than one cancer registry with the same or related diagnosis.

As in previous findings (10), linkage with state death certificates identified the majority of deaths among deceased cancer patients registered in the FCDS (91.6\%) and the NYSCR (96.9\%), whereas linkage with the NDI identified additional deaths among patients who died in the state where they were registered and deaths that occurred in a different state.

NDI identified deaths that were missed through routine death clearance for several possible reasons. First, death clearance is usually performed once per death year and near the end of the diagnosis year. If an incident record or death certificate is reported late to the registry or vital records offices, the record or certificate may not be available at the time of death clearance. Second, the matching algorithms used by the registries differ from those used by NDI; the former uses probabilistic linkages while the latter uses multiple deterministic linkages (11), and deaths may be missed by one or the other. However, a side-by-side comparison of state (probabilistic) and NDI (deterministic) linkage results using Georgia incidence and death data yielded similar results (K. C. Ward, $\mathrm{PhD}, \mathrm{MPH}$, Georgia Center for Cancer Statistics, personal communication), so this difference in algorithms probably does not explain the missing deaths. Third, some data-exchange agreements, such as those with the Florida vital records office, may limit the use of exchanged death certificate information to statistical reporting. As a result, the FCDS was missing information on nearly $1 \%$ of deceased cancer patients who died out of state and whose death certificates were not shared with the FCDS. Fourth, death clearance is used to ascertain missing incident cases, and registry staff may use only cancer-related deaths to expedite the process. If a patient did not die from cancer, the death would be missed.

In this study, most NDI matches were for deaths that occurred among cancer patients who were diagnosed in one state (the diagnosis state) and moved and died as a resident of a different state (the death state). Because the death occurred to a resident of a different state, the cancer registry in the diagnosis state would have no knowledge of the death if the registry relies on linkage with state death certificate records to ascertain deaths.

The opinions expressed by authors contributing to this journal do not necessarily reflect the opinions of the U.S. Department of Health and Human Services, the Public Health Service, the Centers for Disease Control and Prevention, or the authors' affiliated institutions. 
Most cancer patients who died in a different state than the one in which they were presumably diagnosed were also registered as incident cases in the death state's cancer registry. Among the 4,657 FCDS patients who died in New York State, 69.2\% were registered in the NYSCR and of the 2,740 NYSCR patients who died in Florida, 66.0\% were registered in the FCDS. A small number of these patients (233 in the NYSCR and 275 in the FCDS) were reported as DCO cases in the death state's cancer registry. These cases could be removed from the registry regardless of their cause of death because the cancer was diagnosed while the patient was a resident in a different state. Death certificates do not always accurately reflect the true cause of death $(12,13)$; therefore, it seems reasonable to remove these cases regardless of agreement between the coded cause of death and the coded cancer at diagnosis.

Recently, the FCDS and the NYSCR sent data on incident cases spanning their complete years of operations to NDI and conducted data exchange with a focus on removing erroneous DCO cases. Through this process, 1,300 additional DCO cases were removed from the NYSCR database (B.Q., unpublished data, 2012). However, this process left numerous potential duplicate cases that were registered as non-DCO incident cases. Of these, most were registered in the other state's cancer registry with the same diagnosis in both registries. Most of these cases were reported as a single primary cancer in both registries and had similar diagnosis dates. Further investigation is needed to resolve these potential duplicate case reports. To resolve these cases, it will be necessary to develop procedures to determine usual residence at diagnosis (5). For example, a cancer patient may reside in more than one state during the year, spending winter months in a southern state, such as Florida, and summer months in a northern state, such as New York. For the purpose of being enumerated by the US Census, only one usual residence is recognized (14). If similar rules were adopted by cancer registries, it might help ensure agreement between the numerator (incident cases) and the denominator (population counts) when calculating cancer incidence rates.

Information on patients who are diagnosed or treated for cancer, regardless of where they reside, is required by public law (15) to be reported to the cancer registry in the state where the medical services are performed. The registry then sends this information to the cancer registry in the state where the patient resides, provided the patient's correct residence is known and data-exchange agreements are in place. This scenario is complicated when a cancer patient changes residence in the middle of care, for example, to be closer to family and friends. Without querying the cancer patient directly, it may be difficult to identify the original place of residence.
The issue of duplicate case reporting within cancer registries is well recognized $(16,17)$. NAACCR has standards for reporting high-quality cancer incidence data, which include the requirement that registries have one or fewer duplicate cases per 1,000 cases reported (18). However, the issue of duplicate case reporting between and among registries has, to our knowledge, not been raised.

Cancer registries in Australia (19), Canada (20), Sweden (21), and the United Kingdom (22) routinely report personal identifiers as well as demographic and case data to their national cancer surveillance organizations. For example, the Canadian Cancer Registry (CCR) is a patient-based system maintained by Statistics Canada (20). The 13 provincial and territorial cancer registries annually report data to the CCR, which conducts internal record linkages to detect duplicate records and match incidence records to death records in its national mortality database (23). Conflicting information and duplicate case reports are resolved through consultation with the provincial and territorial cancer registries that reported the information. In addition, the CCR identifies multiple primary cancers in a cancer patient when the first primary cancer is diagnosed in one province or territory and the subsequent primary cancer is diagnosed in another.

Unlike Canada and elsewhere, the 2 US cancer surveillance systems (NPCR and SEER) are primarily case-based systems. Because NPCR and SEER registries do not report personal identifiers to their surveillance programs, identifying inter-registry duplicate case reports or multiple primary cancer cases registered in the same patient but in different cancer registries is not possible.

Although the total number of potential duplicate cases identified in this study was less than $1 \%$ of all incident cases in both the FCDS and the NYSCR, the finding that most deceased cancer patients whose deaths were reported in both the FCDS and the NYSCR had the same cancer site (and of these, a similar date of diagnosis) suggests that the impact of duplicate case reporting could be much higher if linkages were extended to include living cancer patients and were performed among cancer registries in the United States. Many US registries operate in small geographic areas and in population centers close to bordering states (Figure). The challenges posed by inter-registry duplicate cases among cancer registries in the United States are likely to increase: the number of annual cancer incident cases is projected to double from 2000 to 2050 (24); the US population is mobile (25); and cancer patients are living longer after diagnosis $(2,26)$.

\footnotetext{
The opinions expressed by authors contributing to this journal do not necessarily reflect the opinions of the U.S. Department of Health and Human Services, the Public Health Service, the Centers for Disease Control and Prevention, or the authors' affiliated institutions.
} 


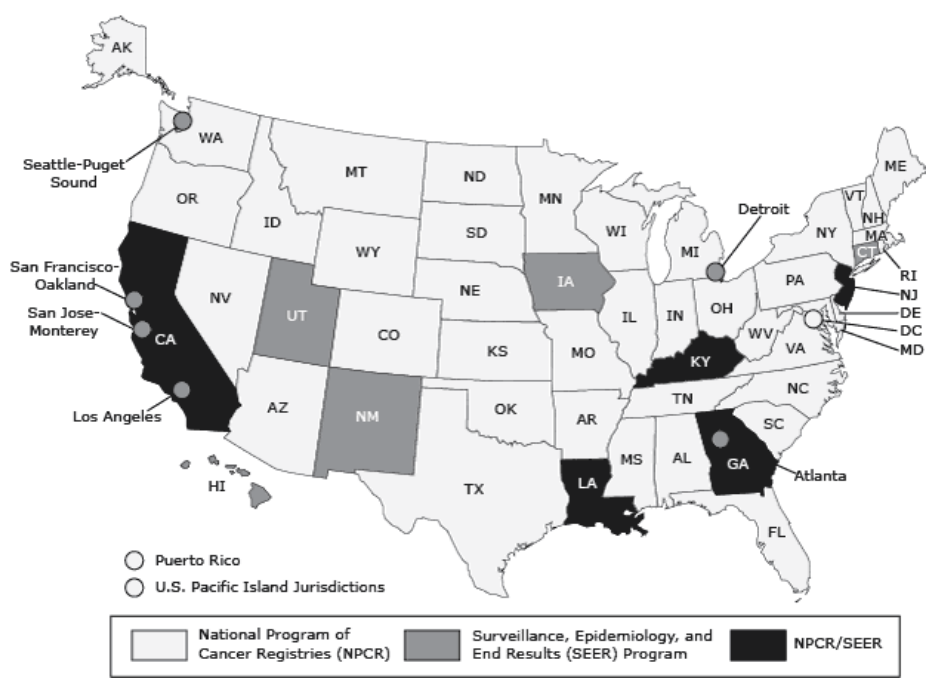

Figure. State, territory, and metropolitan-area cancer registries participating in the National Program of Cancer Registries or the Surveillance, Epidemiology, and End Results programs or both programs as of 2000. Source: US Cancer Statistics Working Group (27).

NDI identified DCO cases that were, but should not have been, registered in the death state's cancer registry. Registries initiating NDI linkages should consider sharing relevant information with death state registries to remove erroneous DCO cases in the death state's registry. NDI also identified a large proportion of potential duplicate cases. Standards are needed to assign primary residence when multiple registries report the same case. This study probably underestimated the number of potential duplicate cases between the FCDS and the NYSCR because the analysis was limited to deceased patients.

\section{Acknowledgments}

We thank Dr Lillian Ingster, director of the NDI at CDC's National Center for Health Statistics, for her review and thoughtful comments on this manuscript. This work was supported by CDC through cooperative agreement DP003872 with the FCDS and cooperative agreements DP000783 and DP003897 with the NYSCR. There are no financial disclosures from any of the authors. The findings and conclusions in this report are those of the authors and do not necessarily represent the official position of CDC.

\section{Author Information}

Corresponding Author: Hannah K. Weir, PhD, Division of Cancer Prevention and Control, Centers for Disease Control and Prevention, 4770 Buford Hwy, MS-F76, Atlanta, GA 30341. Telephone: 770-488-3006. E-mail: hbw4@cdc.gov.
Author Affiliations: Brad Wohler, Jill A. MacKinnon, Florida Cancer Data System, Miami, Florida; Baozhen Qiao, Maria J. Schymura, New York State Cancer Registry, Albany, New York.

\section{References}

1. US Cancer Statistics Working Group. United States cancer statistics: 1999-2009 incidence and mortality web-based report. US Department of Health and Human Services, Centers for Disease Control and Prevention, and National Cancer Institute; 2013. www.cdc.gov/uscs. Accessed April 14, 2014.

2. Howlader N, Noone AM, Krapcho M, Garshell J, Neyman N, Altekruse SF, et al, editors. SEER cancer statistics review, 1975-2010. Bethesda (MD): National Cancer Institute. Based on November 2012 SEER data submission, posted to the SEER website, 2013. http://seer.cancer.gov/csr/1975_2010/. Accessed April 14, 2014.

3. Copeland G, Lake A, Firth R, Wohler B, Wu XC, Stroup A, et al, editors. Cancer in North America: 2006-2010. Volume 1: Combined cancer incidence for the United States, Canada and North America. Springfield (IL): North American Association of Central Cancer Registries, Inc; 2013. http:// www.naaccr.org/DataandPublications/CINAPubs.aspx. Accessed April 14, 2014.

4. Jemal A, Simard EP, Dorell C, Noone AM, Markowitz LE, Kohler B, et al. Annual report to the nation on the status of cancer, 1975-2009, featuring the burden and trends in human papillomavirus (HPV)-associated cancers and HPV vaccination coverage levels. J Natl Cancer Inst 2013;105(3):175-201.

5. Thornton M, editor. Standards for cancer registries volume II: data standards and data dictionary, record layout version 12.2, 16th edition. North American Association of Central Cancer Registries, Inc; 2013 . http://www.naaccr.org/ StandardsandRegistryOperations/VolumeII.aspx. Accessed April 14, 2014.

6. Seiffert J, McKeen K. Death clearance. In: Menck HR, Deapen D, Phillips JL, Tucker TC, editors. Central cancer registries: design, management and use. 2nd edition. Dubuque (IA): Kendall/Hunt Publishing Company; 2007. p .101-110.

7. National Death Index. National Center for Health Statistics, Centers for Disease Control and Prevention, Department of Health and Human Services; 2009. http://www.cdc.gov/nchs/ data_access/ndi/about_ndi.htm. Accessed April 14, 2014.

8. Linking cancer registry data with the National Death Index (NDI): information and steps for a successful linkage - part 1. North American Association of Central Cancer Registries, Inc; 2010 . http://naaccr.org/EducationandTraining/ TownHallWebinars.aspx. Accessed April 14, 2014.

The opinions expressed by authors contributing to this journal do not necessarily reflect the opinions of the U.S. Department of Health and Human Services, the Public Health Service, the Centers for Disease Control and Prevention, or the authors' affiliated institutions. 
9. Site recode SEER. ICD-O-3 (1/27/2003) definition. National Cancer Institute, US Department of Health and Human Services; 2003. http://seer.cancer.gov/siterecode/ icdo3_d01272003. Accessed April 14, 2014.

10. Johnson CJ, Weir HK, Fink AK, German RR, Finch JL, Rycroft RK, et al. The impact of National Death Index linkages on population-based cancer survival rates in the United States. Cancer Epidemiol 2013;37(1):20-8.

11. National Death Index — matching criteria. National Center for Health Statistics, Centers for Disease Control and Prevention, US Department of Health and Human Services; 2009. http:// www.cdc.gov/nchs/data/ndi/NDICriteria_Front.pdf. Accessed April 14, 2014.

12. German RR, Fink AK, Heron M, Stewart SL, Johnson CJ, Finch JL, et al. The accuracy of cancer mortality statistics based on death certificates in the United States. Cancer Epidemiol 2011;35(2):126-31.

13. Johnson CJ, Hahn CG, Fink AK, German RR. Variability in cancer death certificate accuracy by characteristics of death certifiers. Am J Forensic Med Pathol 2012;33(2):137-42.

14. Residence rule and residence situations for the 2010 Census. US Census Bureau. http://www.census.gov/population/www/ cen2010/resid_rules/resid_rules.html. Accessed April 14, 2014.

15. Cancer Registries Amendment Act, Pub. L. No. 102-515, 106 Stat. 3372 (1992).

16. Izquierdo JN, Schoenbach VJ. The potential and limitations of data from population-based state cancer registries. Am J Public Health 2000;90(5):695-8.

17. National Research Council. Enhancing data systems to improve the quality of cancer care. Washington (DC): The National Academies Press; 2000.

18. Weir HK, Tucker TC. NAACCR registry certification. In: Menck HR, Deapen D, Phillips JL, Tucker TC, editors. Central cancer registries: design, management and use, 2nd edition. Dubuque (IA): Kendall/Hunt Publishing Company; 2007. p. 223-236.

19. Australia cancer database 2009 data quality statement, identifying and definitional attributes. Australian Institute of Health and Welfare, Australian Government. http:// meteor.aihw.gov.au/content/index.phtml/itemId/500417. Accessed April 14, 2014.

20. Canadian cancer registry. Statistics Canada, Government of Canada. http://www23.statcan.gc.ca/imdb/ p2SV.pl?Function $=$ getSurvey $\&$ SDDS $=3207 \&$ lang $=e n \& d b=i m$ db\&adm=8\&dis=2. Accessed April 14, 2014.
21. Incidence in Sweden 2011. Health and medical care cancer statistics, official statistics of Sweden. http:// www.socialstyrelsen.se/lists/artikelkatalog/attachments/18919/ 2012-12-19.pdf. Accessed April 14, 2014.

22. Quality and methodology information: cancer statistics registrations. Office for National Statistics; 2012. http:// www.ons.gov.uk/ons/guide-method/method-quality/quality/ quality-information/health-and-social-care/index.html. Accessed April 14, 2014.

23. Vital statistics — death database. Statistics Canada. http:// $\mathrm{w}$ w w 23 . s $\mathrm{t}$ a $\mathrm{t} \mathrm{c} \mathrm{a}$. g c . c a / i m d b / p2SV.pl?Function=getSurvey\&SDDS $=3233 \&$ Item_Id=1635\&1 ang=en. Accessed April 14, 2014.

24. Edwards BK, Howe HL, Ries LA, Thun MJ, Rosenberg HM, Yancik R, et al. Annual report to the nation on the status of cancer, 1973-1999, featuring implications of age and aging on U.S. cancer burden. Cancer 2002;94(10):2766-92.

25. Ren P. Lifetime mobility in the United States: 2010, American Community Survey briefs. US Census Bureau; 2011. http:// www.census.gov/prod/2011pubs/acsbr10-07.pdf. Accessed June 18, 2014.

26. Ries LAG, Young JL, Keel GE, Eisner MP, Lin YD, Horner M-J, editors. SEER survival monograph: cancer survival among adults: US SEER Program, 1988-2001, patient and tumor characteristics. Bethesda (MD): National Cancer Institute, SEER Program, NIH Pub. No. 07-6215; 2007.

27. US Cancer Statistics Working Group. United States cancer statistics: 2004 incidence and mortality. Atlanta (GA): US Department of Health and Human Services, Centers for Disease Control and Prevention and National Cancer Institute; 2007.

\footnotetext{
The opinions expressed by authors contributing to this journal do not necessarily reflect the opinions of the U.S. Department of Health and Human Services, the Public Health Service, the Centers for Disease Control and Prevention, or the authors' affiliated institutions.
} 


\section{Tables}

Table 1. Linkage of State Vital Records and National Death Index (NDI) for Cancer Patients in the Florida Cancer Data System (FCDS) and the New York State Cancer Registry (NYSCR), 1996-2005

\begin{tabular}{|l|r|r|}
\hline Category & FCDS, $\mathbf{n}$ & NYSCR, $\mathbf{n}$ \\
\hline Cancer incident cases diagnosed & 997,290 & 952,663 \\
\hline Deaths identified among incident cases & 434,526 & 401,463 \\
\hline Deaths identified through linkage with state death certificate records & 398,196 & 389,164 \\
\hline Died in state where diagnosis was made & 398,196 & 383,343 \\
\hline Died outside of state where diagnosis was made & 0 & 5,821 \\
\hline Died in reciprocal state ${ }^{a}$ & 0 & 1,488 \\
\hline Deaths identified through linkage with NDI & 36,330 & 12,299 \\
\hline Died in state where diagnosis was made & 3,464 & 1,398 \\
\hline Died outside of state where diagnosis was made & 32,866 & 10,901 \\
\hline Died in reciprocal state & 4,657 & 2,740 \\
\hline Died in another state & 28,209 & 8,161 \\
\hline
\end{tabular}

a The reciprocal state for Florida is New York, and the reciprocal state for New York is Florida. 
Table 2. Match Results Between Exchange Files and Death State Cancer Registries for Deaths of Cancer Patients in the Florida Cancer Data System (FCDS) and the New York State Cancer Registry (NYSCR), 1996-2005

\begin{tabular}{|c|c|c|}
\hline Category & NYSCR, $n$ & FCDS, $\mathrm{n}$ \\
\hline Exchange files received from reciprocal state for linkage ${ }^{a}$ & 4,657 & 2,740 \\
\hline Matched to a patient in registry of reciprocal state ${ }^{b}$ & 3,222 & 1,808 \\
\hline Registered as a single primary $\mathrm{DCO}^{\mathrm{c}}$ incident case & 233 & 275 \\
\hline Registered as non-DCOC incident case & 2,989 & 1,533 \\
\hline At least 1 record has same first 4 digits of the SEER site recode & 2,512 & 1,248 \\
\hline First 4 digits of SEER site recode are different in all records & 477 & 285 \\
\hline
\end{tabular}

Abbreviations: SEER, Surveillance, Epidemiology, and End Results.

a The National Death Index identified 4,657 FCDS cancer patients who died in New York and 2,740 NYSCR cancer patients who died in Florida.

$\mathrm{b}$ The reciprocal state for Florida is New York, and the reciprocal state for New York is Florida.

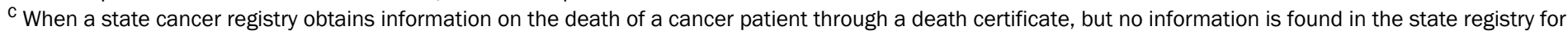
a cancer diagnosis, these death certificate-initiated cases are registered as death certificate-only (DCO) cases in the cancer registry's database.

The opinions expressed by authors contributing to this journal do not necessarily reflect the opinions of the U.S. Department of Health and Human Services, the Public Health Service, the Centers for Disease Control and Prevention, or the authors' affiliated institutions. 
Table 3. Matched-Case Results Among Cancer Patients Who Were Registered In Both the Florida Cancer Data System (FCDS) and the New York State Cancer Registry (NYSCR) With One or More Similar Diagnoses, 1996-2005a

\begin{tabular}{|c|c|c|c|}
\hline Category & NYSCR and FCDS & NYSCR & FCDS \\
\hline Total patients, $\mathrm{n}$ & 3,760 & 2,512 & 1,248 \\
\hline Total non-DCO ${ }^{\mathrm{b}}$ incident cases that matched, $\mathrm{n}$ & 4,035 & 2,673 & 1,362 \\
\hline \multicolumn{4}{|c|}{ Matched Cases } \\
\hline \multicolumn{4}{|l|}{ Cancer site } \\
\hline Lung and bronchus & $948(23.5)$ & $686(25.7)$ & $262(19.2)$ \\
\hline Colorectal & $472(11.7)$ & $296(11.1)$ & $176(12.9)$ \\
\hline Female breast & $373(9.2)$ & $223(8.3)$ & $150(11.0)$ \\
\hline Prostate & $358(8.9)$ & $227(8.5)$ & $131(9.6)$ \\
\hline Urinary bladder & $266(6.7)$ & $165(6.2)$ & $101(7.4)$ \\
\hline All others & $1,618(40.1)$ & $1,076(40.2)$ & $542(39.8)$ \\
\hline \multicolumn{4}{|c|}{ Difference in time (in months) between diagnosis dates in records of matched cases } \\
\hline$\leq 6$ & $2,970(73.7)$ & $2,017(75.5)$ & $953(70.0)$ \\
\hline $7-12$ & $321(8.0)$ & $199(7.4)$ & $122(9.0)$ \\
\hline $13-24$ & $246(6.1)$ & $156(5.8)$ & $90(6.6)$ \\
\hline$\geq 25$ & $498(12.3)$ & $301(11.3)$ & $197(14.5)$ \\
\hline \multicolumn{4}{|l|}{ Sequence number ${ }^{\mathrm{C}}$} \\
\hline Single primary & $2,912(72.2)$ & $2,043(76.4)$ & $869(63.8)$ \\
\hline First primary of multiple primaries & $582(14.2)$ & $306(11.5)$ & $276(20.3)$ \\
\hline Second or later primary of multiple primaries & $541(13.4)$ & $324(12.1)$ & 217 (15.9) \\
\hline
\end{tabular}

a All values are number (percentage) unless otherwise indicated.

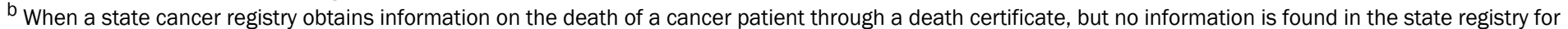
a cancer diagnosis, these death certificate-initiated cases are registered as death certificate-only (DCO) cases in the cancer registry's database.

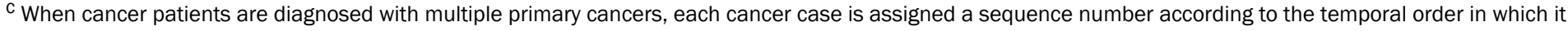
was diagnosed.

The opinions expressed by authors contributing to this journal do not necessarily reflect the opinions of the U.S. Department of Health and Human Services, the Public Health Service, the Centers for Disease Control and Prevention, or the authors' affiliated institutions. 